\title{
For-profit long-term care homes and the risk of COVID-19 outbreaks and resident deaths
}

\author{
Nathan M. Stall MD, Aaron Jones MSc PhD, Kevin A. Brown MSc PhD, Paula A. Rochon MD MPH, \\ Andrew P. Costa PhD
}

Cite as: CMAJ 2020 August 17;192:E946-55. doi: 10.1503/cmaj.201197; early-released July 22, 2020

CMAJ Podcasts: author interview at https://soundcloud.com/cmajpodcasts/201197-res

See related article at www.cmaj.ca/lookup/doi/10.1503/cmaj.201714

\begin{abstract}
BACKGROUND: Long-term care (LTC) homes have been the epicentre of the coronavirus disease 2019 (COVID-19) pandemic in Canada to date. Previous research shows that for-profit LTC homes deliver inferior care across a variety of outcome and process measures, raising the question of whether forprofit homes have had worse COVID-19 outcomes than nonprofit homes.
\end{abstract}

METHODS: We conducted a retrospective cohort study of all LTC homes in Ontario, Canada, from Mar. 29 to May 20, 2020, using a COVID-19 outbreak database maintained by the Ontario Ministry of Long-Term Care. We used hierarchical logistic and count-based methods to model the associations between profit status of LTC homes (for-profit, nonprofit or municipal) and COVID-19 outbreaks in LTC homes, the extent of COVID-19 out- breaks (number of residents infected), and deaths of residents from COVID-19.

RESULTS: The analysis included all 623 Ontario LTC homes, comprising 75676 residents; 360 LTC homes (57.7\%) were for profit, $162(26.0 \%)$ were nonprofit, and 101 (16.2\%) were municipal homes. There were 190 $(30.5 \%)$ outbreaks of COVID-19 in LTC homes, involving 5218 residents and resulting in 1452 deaths, with an overall case fatality rate of $27.8 \%$. The odds of a COVID-19 outbreak were associated with the incidence of COVID-19 in the public health unit region surrounding an LTC home (adjusted odds ratio [OR] 1.91, 95\% confidence interval [Cl] 1.19-3.05), the number of residents (adjusted OR 1.38, 95\% Cl 1.18-1.61), and older design standards of the home (adjusted OR
1.55, 95\% Cl 1.01-2.38), but not profit status. For-profit status was associated with both the extent of an outbreak in an LTC home (adjusted risk ratio [RR] $1.96,95 \% \mathrm{Cl} 1.26-3.05)$ and the number of resident deaths (adjusted RR 1.78, 95\% Cl 1.03-3.07), compared with nonprofit homes. These associations were mediated by a higher prevalence of older design standards in for-profit LTC homes and chain ownership.

INTERPRETATION: For-profit status is associated with the extent of an outbreak of COVID-19 in LTC homes and the number of resident deaths, but not the likelihood of outbreaks. Differences between for-profit and nonprofit homes are largely explained by older design standards and chain ownership, which should be a focus of infection control efforts and future policy.
$\mathbf{L}$

ong-term care (LTC) homes have become the epicentre of the coronavirus disease 2019 (COVID-19) pandemic in Canada, with residents of these care homes accounting for more than $80 \%$ of the country's deaths. ${ }^{1-3}$ Residents of LTC homes are at high risk of contracting severe acute respiratory syndrome coronavirus 2 (SARS-CoV-2), owing to their congregate living arrangements and exposure to staff with asymptomatic or presymptomatic SARS-CoV-2 infection. ${ }^{4-6}$ These residents are also at high risk of morbidity and mortality from COVID-19, as most are older adults with frailty and multimorbidity. ${ }^{7}$ There is widespread concern that despite these predisposing risks, LTC homes were both underprepared and underequipped to protect their residents, and questions have arisen as to whether forprofit LTC homes have had worse COVID-19 outcomes. ${ }^{8,9}$

In Ontario, Canada's most populous province, all residents of LTC homes receive personal and nursing care as well as subsidized accommodation under a publicly funded LTC program. Regardless of this governmental funding, individual LTC homes can be owned and operated by for-profit, nonprofit or municipal (public) entities. ${ }^{10}$ Several observational studies suggest that for-profit LTC homes tend to deliver inferior care across a variety of outcome and process measures. ${ }^{11,12}$ These include lower levels and quality of 
staffing, more complaints from residents and family, higher rates of emergency department visits, more acute care hospital admissions and higher mortality rates. ${ }^{13-22}$ Evidence from the United States suggests that for-profit LTC homes are also more likely to receive deficiency citations for infection control and hand hygiene practices. ${ }^{23,24}$ In light of this evidence and the catastrophic COVID19 epidemic in LTC homes, we examined the association between for-profit status and the risk of COVID-19 outbreaks and death during the peak of the epidemic in Ontario's LTC homes.

\section{Methods}

\section{Study design}

We conducted a retrospective cohort study of all 623 LTC homes in Ontario, from Mar. 29, 2020 - the date of the first reported outbreak in an Ontario LTC home - until May 20, 2020; this period covered the peak of the COVID-19 epidemic in the province's LTC homes. ${ }^{25}$ Our analysis does not include Ontario retirement homes, which are entirely privately funded and not administered by the Ministry of Long-term Care. We followed the Strengthening the Reporting of Observational Studies in Epidemiology (STROBE) reporting guideline and the Reporting of Studies Conducted Using Observational Routinely Collected Health Data (RECORD) statement guidelines. ${ }^{26,27}$

\section{Data sources and explanatory variables}

We obtained all data for this study from the Ontario Ministries of Health and Long-Term Care as part of the COVID-19 Ontario Census Modelling Table. The Modelling Table is sponsored by the Ontario Ministry of Health, Ontario Health and Public Health Ontario and is an ad hoc and voluntary group of senior decision-makers and scientists tasked with creating credible consensus estimates of the impact of COVID-19. Data obtained included LTC home-level data from the Long-Term Care Inspections Branch on the cumulative number of resident COVID-19 cases and deaths. These data are collected daily by inspectors across the province of Ontario, who contact LTC homes and input data on outbreaks into a COVID-19 case tracking tool. The tracking tool includes LTC deaths both for residents who died in LTC facilities and for residents who died in other settings but were still occupying an LTC bed; the tool does not capture residents who were permanently discharged from LTC facilities and died in another setting. Data from the tracking tool have demonstrated excellent correlation when compared with other sources of provincial data collecting COVID-19 cases and deaths. For counts of COVID-19 cases in LTC facilities, the tracking tool has Pearson correlation coefficients of 0.952 and 0.914 with the integrated Public Health Information System (iPHIS) and Ontario Laboratories Information System databases, respectively. ${ }^{28,29}$ For LTC deaths from COVID-19, the tracking tool has Pearson correlation coefficients of 0.913 and 0.904 with the iPHIS and coroner databases, respectively. ${ }^{28}$ The tracking tool also contains information on the profit status of the province's LTC homes, which comprises forprofit homes (proprietary homes that are either owner operated or part of corporate chains), nonprofit homes (charitable, religious and community agencies) and municipal public homes (municipally run; employees are municipal government staff). ${ }^{30}$
Additional LTC home-level data obtained from the Ontario Ministry of Long-Term Care included number of licensed beds; number of active residents in LTC homes as of Mar. 31, 2020; the specific mix of bed occupancy types (1, 2 or 4 residents per room); the ratio of full-time equivalent staff to beds in the LTC home; presence and size of LTC home chains; and the age of the design of the LTC home. The age of design is determined by a structural classification of the home's design standard. ${ }^{31}$ In 1972, Ontario's Nursing Home Act was amended to include standards, including those for the physical plant (permitting 4 beds per room with 1 wash basin and 1 flush toilet; since the 1998 update in these design standards, only single and double rooms have been permitted). ${ }^{30}$ We classified LTC homes that exceed 1972 design standards as having "newer design standards," and those homes that meet or fall below 1972 design standards as having "older design standards." Homes with older design standards have smaller room sizes, fewer single-occupancy rooms and more shared washrooms (Appendix 1, Table S1, available at www.cmaj.ca/ lookup/suppl/doi:10.1503/cmaj.201197/-/DC1).

We also measured the cumulative incidence of COVID-19 in the public health unit regions surrounding each LTC home. We calculated this using deidentified line-level data on all confirmed COVID19 cases (as of May 19, 2020) from Ontario's iPHIS database to determine the rate of COVID-19 per thousand individuals (using population data from the 2016 census) for each of Ontario's 35 health regions served by a public health unit. ${ }^{28}$ We excluded residents of LTC homes from the numerator and denominator of the incidence calculation. We calculated the population size of the communities in which each LTC home was located using Statistics Canada's Postal Code Conversion File Plus, with postal codes from the Canada Post Corporation that were current up to and including November 2018; we considered communities with a population size of fewer than 10000 individuals to be rural. ${ }^{32}$

\section{Primary exposure and main outcomes}

The primary exposure of interest was the profit status of the LTC home (for-profit, nonprofit or municipal), and as such the analysis was conducted at the LTC home level rather than at the resident level. The main outcomes of interest were COVID-19 outbreaks in the LTC home (at least 1 resident case), extent of COVID-19 outbreaks (total number of confirmed resident cases among homes with outbreaks) and total number of COVID-19 resident deaths (among homes with outbreaks).

\section{Statistical analysis}

We computed summary statistics to compare, by profit status, characteristics of LTC homes and the number of COVID-19 resident cases and deaths. We used the $\chi^{2}$ test for categorical variables and the Kruskal-Wallis test for continuous variables; we used the exact binomial test to compare the incidence of COVID19 in 1 of Ontario's 35 public health unit regions surrounding each LTC home. We calculated case fatality rates as the proportion of residents who died of COVID-19 compared with the total number of residents with COVID-19.

We created separate multivariable statistical hurdle models for the 3 outcomes of interest. We modelled the risk of a COVID-19 
outbreak in an LTC home with 1 or more resident cases using logistic regression given the binary outcome. We modelled the extent of COVID-19 outbreaks and total number of resident COVID-19 deaths using quasi-Poisson regression with an offset for the log of the number of active residents within an LTC home; this model accounted for overdispersion in outbreak size relative to usual Poisson counts. For all 3 models, we included random intercepts corresponding to each public health unit region..$^{33}$ For each of the 3 outcomes being modelled, we created 3 models, all adjusted for the same factors.

Model 1 included profit status only (unadjusted). Model 2 included profit status and health region characteristics (population size of the location of the LTC home, COVID-19 cases per thousand in the public health unit region surrounding the LTC home); we selected these covariates as factors extrinsic to LTC homes. Model 3 was an explanatory model and included profit status, health region characteristics and LTC home-level factors (number of active residents, age of design standard, staff-to-bed ratio, and presence and size of the chain of LTC homes); we selected these latter covariates as factors intrinsic to LTC homes.

We chose, a priori, to make our main inferences from model 2 , and we used model 3 to examine explanatory LTC home factors related to profit status. We did not include bed occupancy type in the final models as this was colinear with the age of the design standard of the LTC home (Pearson correlation 0.81); we chose the age of the design standard as the covariate of interest, given that this captures aspects of occupancy (only homes with older design standards have 4-person rooms), in addition to other features such as size of common spaces, size of rooms and shared washrooms (Appendix 1, Table S1). As a sensitivity analysis, we reanalyzed model 3 for all 3 outcomes by entering average occupancy, rather than age of the design standard, into the models (Appendix 1, Table S2). We also created bee swarm plots to represent the distribution of the extent of COVID-19 outbreaks and the total number of deaths across the profit status of LTC homes and age of design standards and chain ownership.

We selected all covariates a priori on the basis of a review of the literature and the expert opinions of infectious disease epidemiologists, as well as specialists in geriatric and LTC medicine. We performed analyses using SAS statistical software, version 9.4 (SAS Institute Inc). Tests were 2-tailed, and we set the level of statistical significance at $\alpha=0.05$.

\section{Ethics approval}

The study was approved by the Research Ethics Board of the University of Toronto, as well as the Hamilton Integrated Research Ethics Board.

\section{Results}

The analysis included all 623 Ontario LTC homes, comprising 75676 residents; 360 of these homes (57.7\%) were for-profit, 162 (26.0\%) were nonprofit, and 101 (16.2\%) were municipal (Table 1 ). On average, and compared with both nonprofit and municipal homes, for-profit homes were smaller (lowest mean number of licensed beds), had the lowest proportion of single-occupancy rooms, had older design standards and had the highest proportion of chain ownership.

Overall, 190 (30.4\%) Ontario LTC homes had a COVID-19 outbreak, with a crude cumulative incidence of 66.4 per thousand. The cumulative incidence of outbreaks of COVID-19 in LTC homes was 85.1 per thousand among for-profit homes, 61.4 per thousand among nonprofit homes, and 23.4 per thousand among municipal homes (Table 2). The crude rate of deaths of LTC home residents from COVID-19 was 23.4 per thousand among for-profit homes, 18.2 per thousand among nonprofit homes, and 5.8 per thousand among municipal homes. The case fatality rate among LTC home residents was $27.5 \%$ among for-profit homes, $29.7 \%$ among nonprofit homes, and $25.0 \%$ among municipal homes.

\section{Odds of an outbreak of COVID-19 in LTC homes}

There were 190 (30.5\%) COVID-19 outbreaks among Ontario's LTC homes, with 110 (30.6\%) occurring in for-profit homes, 55 (34.0\%) in nonprofit homes and 25 (24.8\%) in municipal homes (Table 2). In the unadjusted (model 1 ) and health region characteristicsadjusted (model 2) logistic regression models, profit status of LTC homes was not significantly associated with the odds of an outbreak of COVID-19 in the LTC home (Table 3). In the fully adjusted explanatory model (model 3 ), the cumulative incidence of COVID19 in the public health unit region surrounding the LTC home (adjusted odds ratio [OR] 1.91, 95\% confidence interval [CI] 1.193.05; per increase in $1 / 1000$ COVID-19 cumulative incidence), the total number of active residents (adjusted OR 1.38, 95\% Cl 1.181.61; per 50 beds), and older design standards of LTC homes (adjusted OR 1.55, 95\% Cl 1.01-2.38) were significantly associated with the odds of an outbreak of COVID-19 in LTC homes.

\section{Extent of COVID-19 outbreaks in LTC homes}

Among LTC homes with a COVID-19 outbreak, an average of $23.8 \%$ of all residents in for-profit homes had COVID-19, whereas on average $17.2 \%$ and $7.1 \%$ of all residents in nonprofit and municipal homes had COVID-19, respectively (Table 2). Of the 15 LTC homes with the highest incidence rates, 12 were for-profit homes with older design standards and chain ownership (Figure 1). In both unadjusted (risk ratio [RR] 1.83, 95\% Cl 1.18-2.84) and health region characteristics-adjusted quasi-Poisson regression models (adjusted RR 1.96, 95\% Cl 1.26-3.05), for-profit status was significantly associated with the extent of the outbreak of COVID19 in the LTC home (total number of resident cases) compared with nonprofit status (Table 4). The risk associated with for-profit status was even greater when municipal homes were the referent group in the model (Appendix 1, Table S3).

In the fully adjusted explanatory model, the relationship with for-profit status was attenuated (adjusted RR 0.96, 95\% Cl 0.571.61 ), whereas both the number of COVID-19 cases per thousand in the public health unit region surrounding the LTC home (adjusted RR 1.65, 95\% Cl 1.02-2.67), older design standards of LTC homes (adjusted RR 1.88, 95\% Cl 1.27-2.79), and chain ownership (adjusted RR 1.84, 95\% Cl 1.08-3.15) were significantly associated with the extent of an outbreak of COVID-19 in an LTC home, whereas total number of active residents was protective (adjusted RR 0.84, 95\% Cl 0.73-0.95; per 50 beds). 
Table 1: Characteristics of all 623 Ontario long-term care homes, by profit status

Profit status of LTC home

\begin{tabular}{|c|c|c|c|c|}
\hline Measure & $\begin{array}{l}\text { No. }(\%)^{\star} \text { of for-profit } \\
\begin{array}{c}\text { LTC homes } \dagger \\
n=360\end{array}\end{array}$ & $\begin{array}{l}\text { No. }(\%)^{\star} \text { of nonprofit } \\
\text { LTC homes } \ddagger \\
n=162\end{array}$ & $\begin{array}{c}\text { No. }(\%)^{\star} \text { of } \\
\text { municipal LTC } \\
\text { homes } \S \\
n=101\end{array}$ & $p$ valueฯ \\
\hline No. of residents, mean & 113.2 & 119.6 & 155.2 & $<0.001$ \\
\hline Older design standard ${ }^{\star \star}$ & $193(53.6)$ & $30(18.5)$ & $12(11.9)$ & $<0.001$ \\
\hline \multicolumn{5}{|l|}{ Accommodation type } \\
\hline$\%$ single occupancy, mean & 31.6 & 49.2 & 52.8 & $<0.001$ \\
\hline$\%$ double occupancy, mean & 38.5 & 39.9 & 39.7 & 0.52 \\
\hline$\%$ quadruple occupancy, mean & 28.3 & 8.7 & 6.6 & $<0.001$ \\
\hline \multicolumn{5}{|l|}{ LTC home chains } \\
\hline$\geq 20$ homes & $145(40.3)$ & $0(0)$ & $0(0)$ & \multirow[t]{4}{*}{$<0.001$} \\
\hline 10-19 homes & $104(28.9)$ & $0(0)$ & $0(0)$ & \\
\hline 2-9 homes & $56(15.6)$ & $50(30.9)$ & $0(0)$ & \\
\hline 1 home: not a chain & $55(15.3)$ & $112(69.1)$ & $101(100)$ & \\
\hline Staff (full-time equivalent): bed ratio, mean & 0.70 & 0.72 & 0.77 & $<0.001$ \\
\hline \multicolumn{5}{|l|}{$\begin{array}{l}\text { Population size of the community in which } \\
\text { the LTC home is situated }\end{array}$} \\
\hline$\geq 500000$ & $145(40.3)$ & $82(50.6)$ & $28(27.7)$ & \multirow[t]{3}{*}{0.002} \\
\hline $10000-499999$ & $143(39.7)$ & $37(22.8)$ & $45(44.5)$ & \\
\hline$<10000$ : rural & $72(20.0)$ & $43(26.5)$ & $28(27.7)$ & \\
\hline $\begin{array}{l}\text { Cumulative incidence of COVID- } 19 \text { in the } \\
\text { public health unit region surrounding the } \\
\text { LTC home }\end{array}$ & 1.00 per 1000 & 1.06 per 1000 & 0.89 per 1000 & 0.045 \\
\hline \multicolumn{5}{|c|}{ 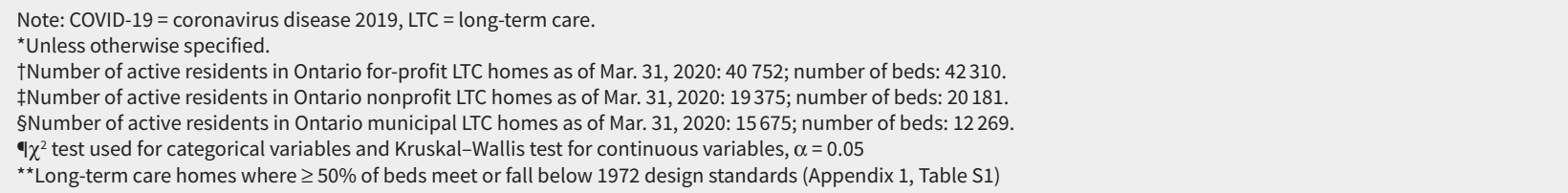 } \\
\hline
\end{tabular}

\section{Number of resident deaths from COVID-19 in an LTC home outbreak}

Among LTC homes with a COVID-19 outbreak, on average $6.5 \%$ of all residents in for-profit homes died of COVID-19, whereas on average $5.5 \%$ and $1.7 \%$ of all residents in nonprofit and municipal homes died of COVID-19, respectively (Table 2). Of the 10 homes with the highest death rates, 7 were for-profit-homes with older design standards and chain ownership (Figure 2). Quasi-Poisson regression modelling showed that for-profit status was associated with the total number of COVID-19 deaths among LTC home residents in the health region characteristics-adjusted model (adjusted RR 1.78, 95\% Cl 1.03-3.07) but not the unadjusted model (RR 1.67, 95\% Cl 0.99-2.73) (Table 5). Again, the risk associated with for-profit status was even greater when municipal homes were the referent group in the model (Appendix 1, Table S3).

In the fully adjusted explanatory model, the relationship with for-profit status was attenuated (adjusted RR 0.82, 95\% Cl $0.44-$ 1.54). Older design standards in LTC homes (adjusted RR 2.08, 95\% $\mathrm{Cl} 1.28-3.36$ ) and chain ownership (adjusted RR 1.89, 95\% Cl 1.00-3.59) were significantly associated with the risk of the total number of deaths from COVID-19 among LTC home residents, whereas number of active residents was protective (adjusted RR 0.81, 95\% $\mathrm{Cl}$ 0.70-0.95; per 50 beds).

\section{Sensitivity analyses}

Reanalyzing model 3 for all 3 outcomes by entering average occupancy rather than age of the design standard yielded similar effect estimates for the associations with for-profit status (Appendix 1, Table S2).

\section{Interpretation}

In this study of all 623 LTC homes in Ontario, Canada, we found that the odds of an outbreak of COVID-19 in an LTC home was associated with the incidence of COVID-19 in the public health unit region surrounding the LTC home, the total number of active residents, and older design standards, but not for-profit status. Among LTC homes with a confirmed COVID-19 outbreak, forprofit status was associated with a 1.96-fold (1.26-3.05) increase in the extent of outbreaks and a 1.78-fold (1.03-3.07) increase in 
Table 2: COVID-19 outbreaks and deaths in Ontario long-term care homes, by profit status (Mar. 29 to May 20, 2020)

\begin{tabular}{|c|c|c|c|c|}
\hline \multirow[b]{2}{*}{ Measure } & \multicolumn{3}{|c|}{ Profit status of LTC home } & \multirow[b]{2}{*}{$p$ valueף } \\
\hline & $\begin{array}{l}\text { No. }(\%)^{\star} \text { of for-profit } \\
\text { LTC homes } \dagger \\
n=360\end{array}$ & $\begin{array}{l}\text { No. }(\%)^{\star} \text { of nonprofit } \\
\text { LTC homes } \ddagger \\
n=162\end{array}$ & $\begin{array}{c}\text { No. }(\%)^{\star} \text { of } \\
\text { municipal LTC } \\
\text { homes§ } \\
n=101\end{array}$ & \\
\hline \multicolumn{5}{|l|}{ COVID-19 outbreaks } \\
\hline Any LTC home outbreak & $154(42.8)$ & $73(45.1)$ & $41(40.6)$ & 0.77 \\
\hline Outbreaks involving both residents and staff & $51(14.2)$ & $29(17.9)$ & $13(12.9)$ & 0.44 \\
\hline Outbreaks involving residents only & $59(16.4)$ & $26(16.0)$ & $12(11.9)$ & 0.53 \\
\hline Outbreaks involving staff only & $44(12.2)$ & $18(11.1)$ & $16(15.8)$ & 0.51 \\
\hline \multicolumn{5}{|l|}{ COVID-19 outbreaks involving residents } \\
\hline Total no. of COVID-19 cases & 3599 & 1239 & 380 & - \\
\hline Cumulative incidence of COVID-19 cases & 85.1 per 1000 & 61.4 per 1000 & 23.4 per 1000 & $<0.001$ \\
\hline Homes with a resident outbreak & $110(30.6)$ & $55(34.0)$ & $25(24.8)$ & 0.29 \\
\hline $\begin{array}{l}\text { Percentage of residents infected per outbreak home, } \\
\text { median (IQR) }\end{array}$ & $\begin{array}{c}4.8 \\
(1.1-49.6)\end{array}$ & $\begin{array}{c}5.6 \\
(1.5-33.8)\end{array}$ & $\begin{array}{c}1.1 \\
(0.6-4.6)\end{array}$ & 0.01 \\
\hline No. of cases per outbreak home, median (IQR) & $5(1-55)$ & $10(1-35)$ & $2(1-10)$ & 0.20 \\
\hline \multicolumn{5}{|l|}{ COVID-19 resident deaths } \\
\hline Total no. of COVID-19 deaths & 989 & 368 & 95 & - \\
\hline COVID-19 death rate & 23.4 per 1000 & 18.2 per 1000 & 5.8 per 1000 & $<0.001$ \\
\hline Homes with any resident death & $51(14)$ & $33(20)$ & $11(11)$ & 0.086 \\
\hline Percentage of resident deaths per home, median (IQR) & $13.0(5.1-19.6)$ & $7.0(2.4-12.7)$ & $2.3(1.0-6.8)$ & 0.0019 \\
\hline Median no. of deaths per home (IQR) & $14(8-27)$ & $10(4-16)$ & $3(2-13)$ & 0.013 \\
\hline Case fatality rate, $\%$ & 27.5 & 29.7 & 25.0 & 0.14 \\
\hline \multicolumn{5}{|c|}{$\begin{array}{l}\text { Note: COVID-19 = coronavirus disease 2019, IQR = interquartile range, LTC = long-term care. } \\
\text { *Unless otherwise specified. } \\
\text { †Number of active residents in Ontario for-profit LTC homes as of Mar. } 31,2020: 40752 ; \text { number of beds: } 42310 . \\
\text { †Number of active residents in Ontario nonprofit LTC homes as of Mar. } 31,2020: 19375 ; \text { number of beds: } 20181 . \\
\text { \$Number of active residents in Ontario municipal LTC homes as of Mar. } 31,2020: 15675 ; \text { number of beds: } 12269 . \\
\text { 9Exact binomial test used for incidence, } \chi^{2} \text { test for categorical variables, and Kruskal-Wallis test for continuous, } \alpha\end{array}$} \\
\hline
\end{tabular}

the number of resident deaths due to COVID-19, compared with nonprofit homes after adjusting for health region characteristics. All comparisons favoured municipal homes, which generally operate with the support of municipal contributions and benefits that allow for greater staffing levels and capital expenditures (Appendix 1, Table S3). ${ }^{13,30}$

The significant association between the risk of an outbreak at an LTC home and the incidence of COVID-19 in the surrounding public health unit region is consistent with emerging literature showing that LTC home staff are important vectors for SARSCoV-2 transmission. ${ }^{5,34}$ During the COVID-19 pandemic, most LTC homes have become relatively closed environments because of restrictions on visitors and resident transfers, meaning that through no fault of their own, infected health care workers are the probable source of many outbreaks. ${ }^{35}$ An earlier study of COVID-19 outbreaks in Ontario LTC homes reported that lagged staff infection was a significant predictor of future resident deaths. ${ }^{34}$ Screening protocols may be missing infected staff who are asymptomatic or minimally symptomatic, and low wages and scarce sick benefits mean that others may be working while ill. $6,8,36$ Many staff are also employed part time and work at multi- ple health care facilities, something that has been linked to SARS-CoV-2 transmission among LTC facilities. ${ }^{5,37}$ Our additional observation associating the number of active residents in an LTC home and the risk of an outbreak may be related to the fact that larger homes require more staff, thereby increasing the number of potential vectors for infection. ${ }^{38}$

Our findings linking for-profit status with both the number of resident cases and deaths within COVID-19 outbreaks at LTC homes appears to be mediated in large part by the higher proportion of outdated design standards (which meet or fall below 1972 standards) and chain ownership in for-profit homes, leading to more widespread transmission of COVID-19. Our data are consistent with previous studies that have found small and inconsistent associations between for-profit status and unfavourable outcomes, including an increased risk of infections in LTC residents. ${ }^{11,12,39-41}$

Our hierarchical model showed that associations favouring nonprofit and municipal homes were attenuated when accounting for the age of a home's design standards. Newer design standards provide for larger and more private room accommodations, as well as less crowded and self-contained common 
Table 3: Odds of a COVID-19 outbreak in a long-term care home, by profit status

\begin{tabular}{|c|c|c|c|}
\hline Variable & $\begin{array}{c}\text { Model } 1 \\
\text { (profit status only), } \\
\text { adjusted OR }(95 \% \mathrm{Cl})\end{array}$ & $\begin{array}{c}\text { Model } 2 \\
\text { (+ adjustment for } \\
\text { health region } \\
\text { characteristics), } \\
\text { adjusted OR }(95 \% \mathrm{CI})\end{array}$ & $\begin{array}{c}\text { Model } 3 \text { (explanatory) } \\
\text { (+ adjustment for LTC } \\
\text { home characteristics), } \\
\text { adjusted OR ( } 95 \% \mathrm{CI})\end{array}$ \\
\hline \multicolumn{4}{|l|}{ Profit status } \\
\hline Nonprofit (Ref.) & - & - & - \\
\hline For-profit & $1.01(0.64-1.57)$ & $0.96(0.61-1.49)$ & $0.71(0.40-1.25)$ \\
\hline Municipal & $0.83(0.45-1.54)$ & $0.85(0.46-1.58)$ & $0.71(0.36-1.42)$ \\
\hline \multicolumn{4}{|l|}{ Health region characteristics } \\
\hline $\begin{array}{l}\text { COVID-19 cumulative incidence in the public health unit region } \\
\text { (1 case per 1000) }\end{array}$ & - & $2.02(1.20-3.38)$ & $1.91(1.19-3.05)$ \\
\hline \multicolumn{4}{|l|}{ Population } \\
\hline$\geq 500000$ (Ref.) & - & - & - \\
\hline $10000-499999$ & - & $0.57(0.32-1.00)$ & $0.56(0.33-0.95)$ \\
\hline$<10000$ (rural) & - & $0.27(0.13-0.58)$ & $0.39(0.18-0.83)$ \\
\hline \multicolumn{4}{|l|}{ LTC home characteristics } \\
\hline No. of residents (unit of 50) & - & - & $1.38(1.18-1.61)$ \\
\hline Older design standards & - & - & $1.55(1.01-2.38)$ \\
\hline Chain ownership (v. single home) & - & - & $1.47(0.86-2.51)$ \\
\hline Staff (full-time equivalent):bed ratio & - & - & $1.98(0.39-9.97)$ \\
\hline
\end{tabular}

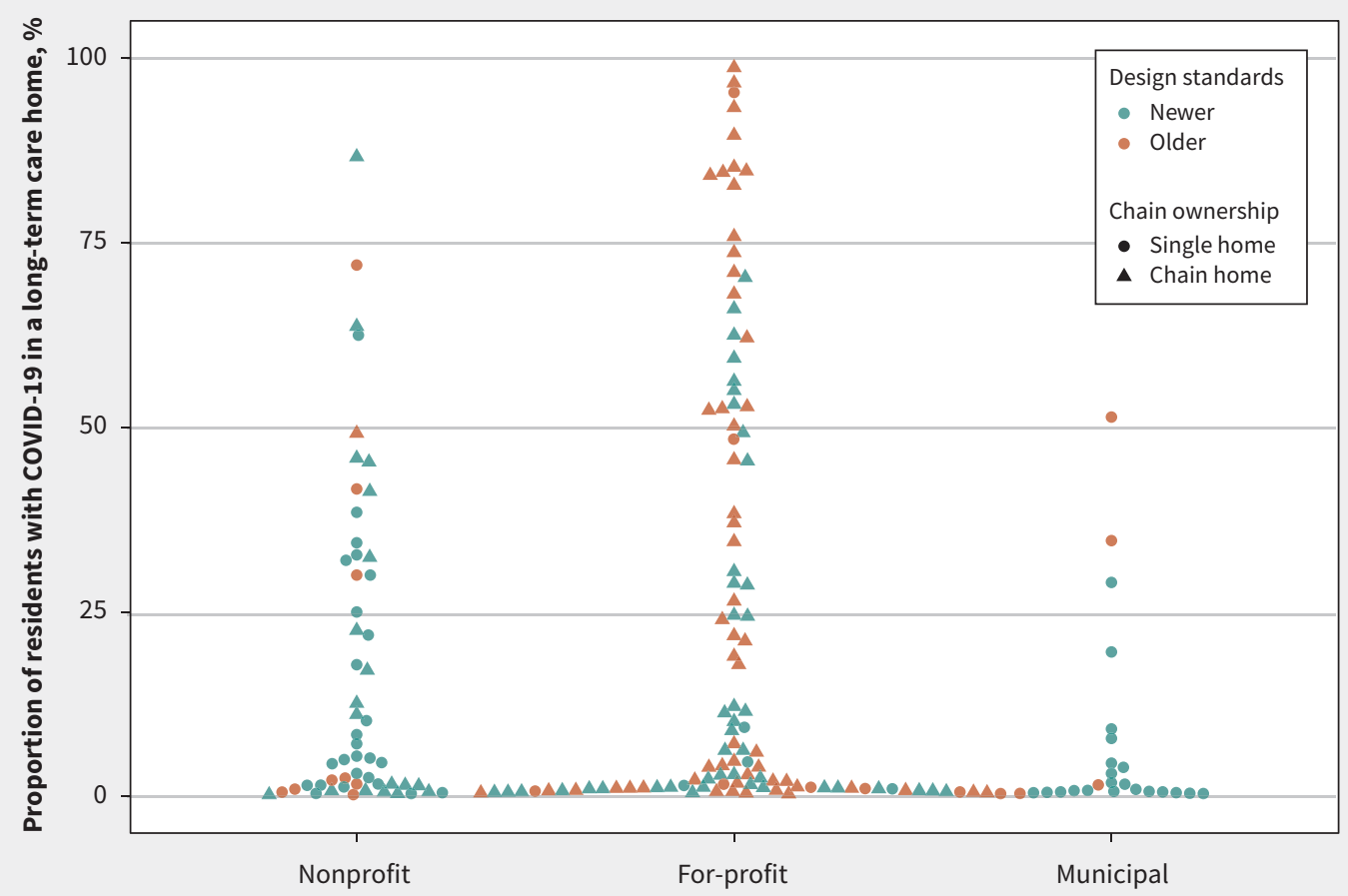

Profit status

Figure 1: Distribution of the extent of outbreaks of coronavirus disease 2019 (COVID-19) in long-term care homes, by profit status. 
Table 4: Extent* of COVID-19 outbreaks in long-term care homes, by profit status

\begin{tabular}{|c|c|c|c|}
\hline Variable & $\begin{array}{c}\text { Model } 1 \\
\text { (profit status only), } \\
\text { adjusted RR }(95 \% \mathrm{CI})\end{array}$ & $\begin{array}{c}\text { Model } 2 \\
\text { (+ adjustment for } \\
\text { health region } \\
\text { characteristics), } \\
\text { adjusted RR }(95 \% \mathrm{CI})\end{array}$ & $\begin{array}{c}\text { Model } 3 \text { (explanatory) } \\
\text { (+ adjustment for LTC } \\
\text { home characteristics), } \\
\text { adjusted RR }(95 \% \mathrm{CI})\end{array}$ \\
\hline \multicolumn{4}{|l|}{ Profit status } \\
\hline Nonprofit (Ref.) & - & - & - \\
\hline For-profit & $1.83(1.18-2.84)$ & $1.96(1.26-3.05)$ & $0.96(0.57-1.61)$ \\
\hline Municipal & $0.60(0.28-1.30)$ & $0.64(0.29-1.40)$ & $0.85(0.40-1.82)$ \\
\hline \multicolumn{4}{|l|}{ Health region characteristics } \\
\hline $\begin{array}{l}\text { COVID-19 cumulative incidence in the public health unit region } \\
\text { (cases per 1000) }\end{array}$ & - & $1.84(1.10-3.08)$ & $1.65(1.02-2.67)$ \\
\hline \multicolumn{4}{|l|}{ Population } \\
\hline$\geq 500000$ (ref) & - & - & - \\
\hline $10000-499999$ & - & $0.65(0.33-1.24)$ & $0.55(0.30-0.99)$ \\
\hline$<10000$ (rural) & - & $0.85(0.22-3.28)$ & $0.53(0.15-1.83)$ \\
\hline \multicolumn{4}{|l|}{ LTC home characteristics } \\
\hline No. of residents (unit of 50) & - & - & $0.84(0.73-0.95)$ \\
\hline Older design standards & - & - & $1.88(1.27-2.79)$ \\
\hline Chain ownership (v. single home) & - & - & $1.84(1.08-3.15)$ \\
\hline Staff (full-time equivalent):bed ratio & - & - & $0.73(0.10-5.35)$ \\
\hline
\end{tabular}

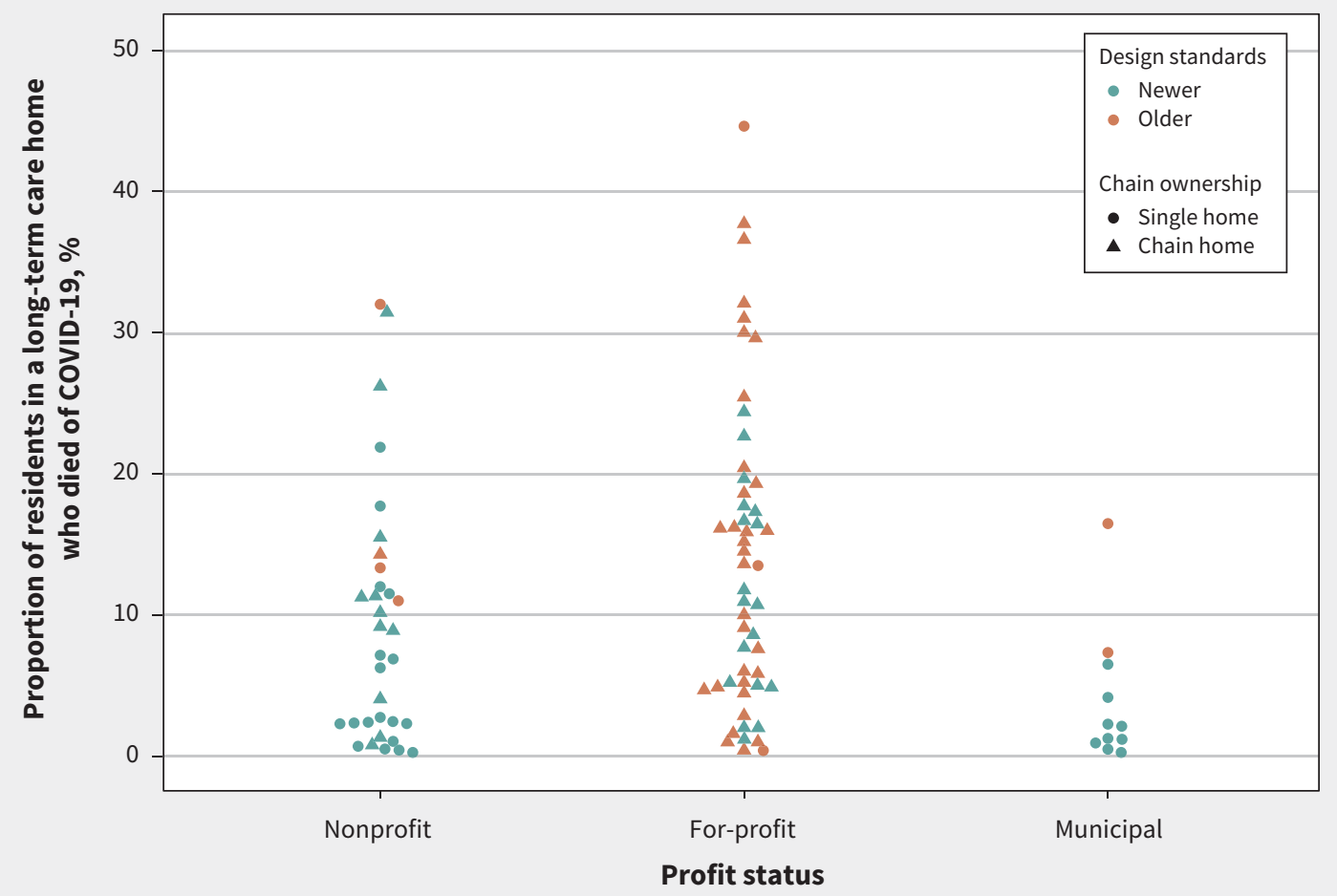

Figure 2: Distribution of the number of deaths from coronavirus disease 2019 (COVID-19) among residents in a long-term care home, by profit status. 
Table 5: Number of deaths from COVID-19 among long-term care home residents, by profit status

\begin{tabular}{|c|c|c|c|}
\hline Variable & $\begin{array}{c}\text { Model 1 } \\
\text { (profit status only), } \\
\text { adjusted RR }(95 \% \mathrm{Cl})\end{array}$ & $\begin{array}{c}\text { Model } 2 \\
\text { (+ adjustment for } \\
\text { health region } \\
\text { characteristics), } \\
\text { adjusted } \mathrm{RR}(95 \% \mathrm{Cl})\end{array}$ & $\begin{array}{c}\text { Model } 3 \\
\text { (+ adjustment for LTC } \\
\text { home characteristics), } \\
\text { adjusted RR ( } 95 \% \mathrm{CI})\end{array}$ \\
\hline \multicolumn{4}{|l|}{ Profit status } \\
\hline Nonprofit (Ref.) & - & - & - \\
\hline For-profit & $1.67(0.99-2.79)$ & $1.78(1.03-3.07)$ & $0.82(0.44-1.54)$ \\
\hline Municipal & $0.50(0.19-1.29)$ & $0.54(0.20-1.49)$ & $0.73(0.28-1.88)$ \\
\hline \multicolumn{4}{|l|}{ Health region characteristics } \\
\hline $\begin{array}{l}\text { COVID-19 cumulative incidence in the public health unit region } \\
\text { (cases per 1000) }\end{array}$ & - & $1.77(0.47-6.60)$ & $1.44(0.81-2.55)$ \\
\hline \multicolumn{4}{|l|}{ Population } \\
\hline$\geq 500000$ (ref) & - & - & - \\
\hline $10000-499999$ & - & $0.62(0.26-1.47)$ & $0.51(0.25-1.05)$ \\
\hline$<10000$ (rural) & - & $0.72(0.12-4.25)$ & $0.40(0.08-1.89)$ \\
\hline \multicolumn{4}{|l|}{ LTC home characteristics } \\
\hline No. of residents (unit of 50 ) & - & - & $0.81(0.70-0.95)$ \\
\hline Older design standards & - & - & $2.08(1.28-3.36)$ \\
\hline Chain ownership (v. single home) & - & - & $1.89(1.00-3.59)$ \\
\hline Staff (full-time equivalent):bed ratio & - & - & $0.84(0.09-8.75)$ \\
\hline
\end{tabular}

spaces, whereas older design standards can have ward-style accommodation and centralized common spaces in which all residents can interact (Appendix 1, Table S1). Beyond promoting quality of life, newer design standards are intended to promote infection prevention and control, given that they limit infection both within resident bedrooms and among areas of a facility. ${ }^{31}$ Further, we observed a protective effect of larger homes with more active residents on the extent of COVID-19 outbreaks and resident deaths, something we suspect is related to homes with new design standards having self-contained "resident home areas" that accommodate no more than 40 residents. ${ }^{42}$

The COVID-19 crisis in Canada's LTC homes has laid bare longstanding issues in how LTC homes are financed, operated and regulated ${ }^{43}$ and already led to sweeping calls for reforms to longterm care, including removing private for-profit businesses from the sector. ${ }^{8,44}$ Our findings suggest that the incidence of COVID-19 in the public health unit region surrounding an LTC home and the size of the home - but not for-profit status - are important risk factors for outbreaks of COVID-19 in LTC homes, whereas forprofit status (with for-profit homes more commonly having outdated design standards and chain ownership) is an important risk factor for transmission of COVID-19 after an outbreak is established in a home. Further, it is important to recognize that not all for-profit homes have worse COVID-19 outcomes; those with older design standards appear to show worse outcomes, likely indicating a failure to upgrade and modernize facilities. With governments such as Ontario's already committing to independent commissions and inquiries into their LTC systems, it is important that policy recommendations and changes consider all root causes of the present crisis, including supporting capital projects to retrofit or rebuild older LTC homes. ${ }^{45}$

\section{Limitations}

The study is limited by a lack of individual-level data on the sociodemographic and clinical characteristics of residents of LTC homes. Given the centralized admission process for LTC facilities in the province of Ontario, we do not expect substantial differences in the resident case-mix between for-profit, nonprofit and municipal homes. By examining all LTC homes in Ontario, we took the maximum sample size available without a priori sample size calculations; post hoc simulations of outbreaks based on the observed distribution of cases among homes confirmed that our analyses had adequate power to detect differences in the extent of COVID-19 outbreaks between forprofit, nonprofit and municipal homes. Our data on staffing were limited to the number of rostered full-time equivalent staff per LTC home and do not necessarily account for the number of staff physically working in a home at any given time. We also could not determine whether nonprofit homes were subcontracting out the provision of care to for-profit entities, and our use of the incidence of COVID-19 in the Ontario public health unit region surrounding each LTC home may have been imprecise for homes proximal to the borders of regions with differing incidences.

Like other sources of data being rapidly collected during the COVID-19 pandemic, data from the Long-Term Care Inspections Branch were not independently validated, and there is potential 
for incompleteness. Because many outbreaks in LTC homes were still ongoing, there is the potential for right censoring of data, whereby actively infected residents who were alive at the end of our study period could still go on to die; this also limited our ability to study outbreaks that involved only staff but had the potential to spread to residents. We also could not account for temporal changes in both access to personal protective equipment within LTC homes and provincial policies in infection prevention and control practices, SARS-CoV-2 testing and staff mobility among homes; however, these factors would mediate rather than confound the observed results. Finally, we did not account for SARS-CoV-2 testing rates, but case fatality rates for COVID-19 in for-profit, nonprofit and municipal homes were similar, suggesting similar levels of case identification.

\section{Conclusion}

We have shown that the risk of an outbreak of COVID-19 at an LTC home was related to the COVID-19 incidence rate in the public health unit region surrounding the home, its total number of beds and older design standards, rather than for-profit status. We did find evidence that for-profit LTC homes have larger COVID-19 outbreaks and more deaths of residents from COVID-19 than nonprofit and municipal homes, and that this finding was mediated by the higher number of for-profit homes with outdated design standards and chain ownership. The COVID-19 pandemic has laid bare long-standing issues in how LTC homes are financed, operated and regulated. ${ }^{45}$ As health systems scramble to prepare LTC homes for successive waves of the COVID-19 pandemic and others search for accountability and solutions to the crisis in the sector, it is important to examine all potential explanations for observed differences in COVID19 outcomes across LTC homes.

\section{References}

1. Barnett ML, Grabowski DC. Nursing homes are ground zero for COVID-19 pandemic JAMA Health Forum 2020 Mar. 24. Available: https://jamanetwork.com/ channels/health-forum/fullarticle/2763666 (accessed 2020 May 1).

2. Hsu AT, Lane N, Sinha SK, et al. Understanding the impact of COVID-19 on residents of Canada's long-term care homes - ongoing challenges and policy responses. London (UK): International Long-Term Care Policy Network; updated 2020 June 4. Available: https://tccovid.org/wp-content/uploads/2020/06/ LTCcovid-country-reports_Canada_June-4-2020.pdf (accessed 2020 July 1).

3. Pandemic experience in the long-term care sector: How does Canada compare with other countries? Ottawa: Canadian Institute for Health Information; 2020. Available: www.cihi.ca/sites/default/files/document/covid-19-rapid-response -long-term-care-snapshot-en.pdf (accessed 2020 July 1 ).

4. D'Adamo H, Yoshikawa T, Ouslander JG. Coronavirus disease 2019 in geriatrics and long-term care: the ABCDs of COVID-19. J Am Geriatr Soc 2020;68:912-7.

5. McMichael TM, Currie DW, Clark S, et al. Epidemiology of COVID-19 in a long-term care facility in King County, Washington. N Engl J Med 2020;382: 2005-11.

6. Hoxha A, Wyndham-Thomas C, Klamer S, et al. Asymptomatic SARS-CoV-2 infection in Belgian long-term care facilities. Lancet Infect Dis 2020; Jul 3; S1473-3099(20)30560-0.

7. Ouslander JG. Coronavirus disease19 in geriatrics and long-term care: an update. J Am Geriatr Soc 2020;68:918-21.

8. Holroyd-Leduc JM, Laupacis A. Continuing care and COVID-19: a Canadian tragedy that must not be allowed to happen again. CMAJ 2020;192:E632-3.

9. Jabbar A, Raza D. Let's keep profit out of long-term care. The Star [Toronto]; 2020 May 6. Available: www.thestar.com/opinion/contributors/2020/05/06/ lets-keep-profit-out-of-long-term-care.html (accessed 2020 May 17).
10. Ronald LA, McGregor MJ, Harrington C, et al. observational evidence of forprofit delivery and inferior nursing home care: When is there enough evidence for policy change? PLoS Med 2016;13:e1001995.

11. Comondore VR, Devereaux PJ, Zhou Q, et al. Quality of care in for-profit and not-for-profit nursing homes: systematic review and meta-analysis. BMJ 2009;339:b2732.

12. Hillmer MP, Wodchis WP, Gill SS, et al. Nursing home profit status and quality of care: is there any evidence of an association? Med Care Res Rev 2005;62:139-66.

13. McGregor MJ, Cohen M, McGrail K, et al. Staffing levels in not-for-profit and forprofit long-term care facilities: Does type of ownership matter? CMAJ 2005;172:645-9.

14. Harrington $\mathrm{C}$, Olney $\mathrm{B}$, Carrillo $\mathrm{H}$, et al. Nurse staffing and deficiencies in the largest for-profit nursing home chains and chains owned by private equity companies. Health Serv Res 2012;47:106-28.

15. Hsu AT, Berta W, Coyte PC, et al. Staffing in Ontario's long-term care homes: differences by profit status and chain ownership. Can J Aging 2016;35:175-89.

16. McGregor MJ, Cohen M, Stocks-Rankin CR, et al. Complaints in for-profit, nonprofit and public nursing homes in two Canadian provinces. Open Med 2011;5:e183-92.

17. Tanuseputro $\mathrm{P}$, Chalifoux M, Bennett $\mathrm{C}$, et al. Hospitalization and mortality rates in long-term care facilities: Does for-profit status matter? J Am Med Dir Assoc 2015;16:874-83.

18. Hirth RA, Grabowski DC, Feng Z, et al. Effect of nursing home ownership on hospitalization of long-stay residents: an instrumental variables approach. Int $J$ Health Care Finance Econ 2014;14:1-18.

19. McGregor MJ, Abu-Laban RB, Ronald LA, et al. Nursing home characteristics associated with resident transfers to emergency departments. Can J Aging 2014;33:38-48.

20. McGregor MJ, Tate RB, McGrail KM, et al. Care outcomes in long-term care facilities in British Columbia, Canada. Does ownership matter? Med Care 2006;44:929-35.

21. Grabowski DC, Feng Z, Hirth R, et al. Effect of nursing home ownership on the quality of post-acute care: an instrumental variables approach. $J$ Health Econ 2013;32:12-21.

22. Damián J, Pastor-Barriuso R, Garcia-Lopez FJ, et al. Facility ownership and mortality among older adults residing in care homes. PLoS One 2019;14:e0197789.

23. Castle NG, Wagner LM, Ferguson-Rome JC, et al. Nursing home deficiency citations for infection control. Am J Infect Control 2011;39:263-9.

24. Castle N, Wagner L, Ferguson J, et al. Hand hygiene deficiency citations in nursing homes. J Appl Gerontol 2014;33:24-50.

25. COVID-19 outbreak guidance for long-term care homes (LTCH). Toronto: Ontario Ministry of Health; 2020 Apr. 15. Available: www.health.gov.on.ca/en/ pro/programs/publichealth/coronavirus/docs/LTCH_outbreak_guidance.pdf (accessed 2020 May 5).

26. Benchimol El, Smeeth L, Guttmann A, et al. The REporting of studies Conducted using Observational Routinely-collected health Data (RECORD) statement. PLoS Med 2015;12:e1001885.

27. von Elm E, Altman DG, Egger M, et al. Strengthening the Reporting of Observational Studies in Epidemiology (STROBE) statement: guidelines for reporting observational studies. BMJ 2007;335:806-8.

28. iPHIS resources. Toronto: Public Health Ontario; 2020. Available: www. publichealthontario.ca/en/diseases-and-conditions/infectious-diseases/ccm/ iphis (accessed 2020 May 17).

29. eHealth Ontario. Ontario Laboratories Information System (OLIS). Toronto: Ontario Health; 2020. Available: www.ehealthontario.on.ca/en/for-healthcare -professionals/ontario-laboratories-information-system-olis (accessed 2020 July 13).

30. Daly T. Dancing the two-step in Ontario's long-term care sector: more deterrence-oriented regulation = ownership and management consolidation. Stud Polit Econ 2015;95:29-58.

31. Long-term care home design manual 2015. Toronto: Ontario Ministry of Health and Long-Term Care; 2015. Available: http://health.gov.on.ca/en/public/ programs/ltc/docs/home_design_manual.pdf (accessed 2020 May 22).

32. Postal code OM conversion file plus (PCCF+). Ottawa: Statistics Canada; 2020 Available: https://www150.statcan.gc.ca/n1/en/catalogue/82F0086X (accessed 2020 June 28)

33. Harrison XA. Using observation-level random effects to model overdispersion in count data in ecology and evolution. PeerJ 2014;2:e616.

34. Fisman D, Bogoch I, Lapointe-Shaw L, et al. Risk factors associated with mortality among residents with COVID-19 in long-term care facilities in Canada. Jama Network Open 2020 July 22. doi: 10.1101/jamanetworkopen.2020.15957.

35. Chow EJ, Schwartz NG, Tobolowsky FA, et al. Symptom screening at illness onset of health care personnel with SARS-CoV-2 infection in King County, Washington. JAMA 2020;323:2087-9.

36. Pollock AM, Clements L, Harding-Edgar L. Covid-19: why we need a national health and social care service. BMJ 2020;369:m1465. 
37. Van Houtven CH, DePasquale N, Coe NB. Essential Long-Term Care Workers Commonly Hold Second Jobs and Double- or Triple-Duty Caregiving Roles. J Am Geriatr Soc 2020 Apr. 27 [Epub ahead of print]. doi: 10.1111/jgs.16509.

38. Baldwin R, Chenoweth L, Dela Rama M, et al. Does size matter in aged care facilities? A literature review of the relationship between the number of facility beds and quality. Health Care Manage Rev 2017;42:315-27.

39. Konetzka RT, Spector W, Shaffer T. Effects of nursing home ownership type and resident payer source on hospitalization for suspected pneumonia. Med Care 2004;42:1001-8.

40. Chou SY. Asymmetric information, ownership and quality of care: an empirical analysis of nursing homes. J Health Econ 2002;21:293-311.

41. Spector WD, Selden TM, Cohen JW. The impact of ownership type on nursing home outcomes. Health Econ 1998;7:639-53.
42. Long-term care facility design manual. Toronto: Ontario Ministry of Health and Long-Term Care; 1999. Available: https://collections.ola.org/mon/ont/H/1999/ LTCdesign_manual.pdf

43. Grabowski DC, Mor V. Nursing home care in crisis in the wake of COVID-19. JAMA 2020 May 22 [Epub ahead of print]. doi: 10.1001/jama.2020.8524.

44. Lessons from a pandemic: union recommendations for transforming longterm care in Canada. North York (ON): Canadian Labour Congress; 2020. Available: http://documents.clcctc.ca/sep/LongTermCare-Report-EN.pdf (accessed 2020 May 19).

45. Ontario announces independent commission into long-term care [media release]. Toronto: Ontario Ministry of Long-Term Care; 2020 May 19. Available: https:// news.ontario.ca/mltc/en/2020/05/ontario-announces-independent-commission -into-long-term-care.html (accessed 2020 May 20).
Competing interests: Andrew Costa reports that he holds the position of Schlegel Chair at McMaster University, which was given as a gift by the Schlegel family (who own Schlegel Villages [a for-profit chain of long-term care and retirement homes] as well as other unrelated businesses). No other competing interests were declared.

\section{This article has been peer reviewed.}

Affiliations: Division of General Internal Medicine and Geriatrics (Stall), Sinai Health System and the University Health Network; Women's College Research Institute (Stall, Rochon), Women's College Hospital; Department of Medicine (Stall, Rochon) and Institute of Health Policy, Management and Evaluation (Stall, Rochon), University of Toronto, Toronto, Ont.; Department of Health Research Methods, Evidence, and Impact (Jones, Costa), McMaster University, Hamilton, Ont.; Infection Prevention and Control (Brown), Public Health Ontario; Dalla Lana School of Public Health (Brown), University of Toronto, Toronto, Ont.; Schlegel Chair in Clinical Epidemiology and Aging (Costa), McMaster Univer- sity; Centre for Integrated Care (Costa), St. Joseph's Health System, Hamilton, Ont.

Contributors: Nathan Stall, Aaron Jones, Kevin Brown and Andrew Costa contributed to the conception and design of the work. All of the authors acquired, analyzed and interpreted the data. Aaron Jones performed the statistical analysis. Nathan Stall drafted the manuscript. All of the authors critically revised the manuscript for important intellectual content and agreed to be accountable for all aspects of the work.

Funding: This research was not funded.

Data sharing: The study protocol and statistical code are available from the authors on request (e-mail: nathan.stall@sinaihealth.ca), with the understanding that the computer programs may rely on coding templates or macros that may be inaccessible or require modification. The data set from this study is held securely at the Ontario Ministry of Health's Capacity Planning and Analytics Division, and data-sharing agreements prohibit making the data set publicly available.
Acknowledgements: The authors gratefully acknowledge the support of Michael Hillmer, Kamil Malikov and Sping Wang from the Ontario Ministry of Health's Capacity Planning and Analytics Division for assistance with data acquisition, interpretation and analysis. Nathan M. Stall is supported by the Department of Medicine's Eliot Phillipson ClinicianScientist Training Program and the Clinician Investigator Program at the University of Toronto, and the Vanier Canada Graduate Scholarship. Paula A. Rochon holds the RTOERO Chair in Geriatric Medicine at the University of Toronto. Andrew P. Costa holds the Schlegel Chair in Clinical Epidemiology and Aging at McMaster University.

Disclaimer: Nathan Stall is an associate editor with CMAJ and was not involved in the editorial decision- making for this article.

Accepted: July 14, 2020

Correspondence to: Nathan Stall, nathan.stall@sinaihealth.ca 